Сухарева О. В.

\begin{abstract}
Аннотация. Цель исследования - определить специфику реализации коннотативной семантики англоязычных художественных онимов в процессе словообразовательной деривации. Научная новизна исследования заключается в описании формирования этноконнотаций у особого разряда ономастической лексики, художественных онимов английского языка, с позиций когнитивной лингвистики и лингвокультурологии. В результате доказано, что значение производных художественных онимов является результатом действия концептуальной деривации, осуществляемой посредством двухуровневого механизма концептуальной интеграции, и детерминировано особенностями национальной культуры.
\end{abstract}

\title{
Word-Formative Derivation of Ethnically Marked Literary Onyms in the English Language
}

\author{
Sukhareva O. V.
}

\begin{abstract}
The paper aims to reveal specificity of realization of connotation meaning of the English literary onyms formed by derivation. Scientific originality of the study lies in the fact that formation of ethnic connotations of a special type of onyms, the English literary onyms, is described from the viewpoint of cognitive linguistics and linguo-culturology. The research findings are as follows: the author proves that meaning of derived literary onyms is formed as a result of conceptual derivation achieved through two-stage conceptual integration. This meaning is determined by specificity of the national culture.
\end{abstract}

\section{Введение}

Актуальность темы исследования определяется необходимостью изучения роли человека в познании и интерпретации окружающей действительности и решения проблемы представленности человека в языке. Антропоцентризм стал ведущим принципом современной парадигмы лингвистического знания, при котором в фокусе научных интересов находится не столько устройство самого языка, сколько человек как уникальный носитель языка и культуры. В настоящее время большое количество исследований направлено на изучение процессов интериоризации знаний в рамках трихотомии «язык - познание - культура». Однако в современной англистике механизмы порождения этноконнотации как проявление интерпретирующей лингвокреативной деятельности носителей языка, обусловленной национально-культурной спецификой их языкового сознания, являются недостаточно изученными. Важность развития положений ономастики с позиций лингвокультурологии и когнитивной лингвистики предопределяет выбор особого разряда ономастической лексики, художественных онимов, в качестве объекта данной работы.

Для реализации поставленной цели необходимо решить следующие задачи: 1) выявить англоязычные художественные онимы, порождающие этноконнотации в процессе словообразовательной деривации, путем сплошной выборки из современных англоязычных лексикографических источников; 2) рассмотреть деривационные процессы вторичной номинации художественных онимов английского языка как проявление концептуальной деривации и описать когнитивные механизмы, обусловливающие развитие коннотативной семантики; 3) проанализировать особенности функционирования производных слов, сложных слов и телескопизмов в газетно-публицистических текстах британских и американских изданий и определить наиболее продуктивные способы словообразования и словообразовательные модели.

Для решения поставленных задач нами использовались следующие методы: аналитический, описательный, сравнение, компонентный анализ, концептуальный анализ, а также морфемно-структурный, количественный, контекстуальный анализы. 
Теоретической базой данного исследования послужили работы Л. В. Бабиной, Е. О. Паршиной [1; 2], О. К. Ирисхановой [7], Е. С. Кубряковой, В. А. Гуреева [9; 10], посвященные когнитивным аспектам словообразования, труды Е. Г. Беляевской [3], О. И. Быковой [5], В. И. Говердовского [6], В. Н. Телия [13], в которых рассматриваются вопросы теории коннотации.

Практическая значимость работы заключается в возможности использования полученных результатов при разработке учебных курсов по лексикологии, лингвокультурологии, теории и практике перевода.

\section{Деривационный потенциал англоязычных художественных онимов}

Динамичный характер языка обусловлен непрерывным развитием и обогащением концептуальных структур сознания в процессе познания мира представителями той или иной лингвокультурной общности. Вторичная языковая интерпретация основана на концептуальной деривации и определяется Н. Н. Болдыревым как «переосмысление и оценка уже имеющихся вербализованных знаний о мире в индивидуальной концептуальной системе человека в соответствии с его мировидением и представлениями о системе норм, стереотипов, ценностей» [4, с. 39]. Согласно Г. И. Кустовой, в этом заключается общий принцип когнитивной деятельности человека: «...человек понимает новое, неосвоенное через данное, освоенное и известное» [11, с. 23].

Прецедентный характер исследуемых нами художественных онимов [12], а также соотнесенность с определенными денотатами, персонажами произведений различных видов искусства, превращают данные имена собственные в «интерпретативно-смысловую бесконечность» [8, с. 148]. Они актуализируют прототипические структуры и концентрируют в себе актуальные для данного социума ценностные установки. Этим объясняется активное использование художественных онимов носителями языка как вторичных номинант при вербализации концептуального содержания.

Вторичная семиотизация в условиях определенной культуры приводит к порождению языковыми единицами этнокультурных коннотаций. Как отмечает О. И. Быкова, интерпретация образно-мотивированного значения детерминирована ассоциативным механизмом порождения коннотации, в котором переплетены лингвистические и экстралингвистические факторы и психофизиологические особенности восприятия действительности при ее первичной интерпретации представителями конкретного этноса [5, с. 33]. Этнокультурная маркированность художественных онимов обусловливает их богатый коннотативный потенциал, который реализуется в результате деривационных процессов вторичной и косвенной номинации (всего выявлено 590 единиц, в том числе вторичные художественные онимы-лексемы, производные слова, телескопизмы, сложные слова и фразеологические единицы). Количественный анализ соотношения деривационных процессов показал, что наиболее продуктивным процессом является семантическая деривация - 70,3\%, словообразовательная деривация составляет $23 \%$, а фразеологизация $-6,7 \%$.

Словообразование и словосложение предоставляют неограниченные возможности при вербализации новых ментальных структур. Помимо выполнения номинативной функции словообразовательная деривация способствует языковой экономии, а также созданию экспрессивного эффекта. Отметим, что в результате исследования были выявлены не только узуальные, зафиксированные в авторитетных лексикографических источниках единицы, но и окказионализмы (125 единиц). В качестве иллюстрации приведем следующие примеры: Grinchitude [14] - пренебрежительное отношение к Рождеству (Grinch - имя злого существа в рассказе Т. С. Гейзела “How the Grinch Stole Christmas”); Flintstoning [21] - перемещение по офису на стуле с колесиками (The Flintstones - герои американского комедийного мультсериала, которые ездят на автомобиле, отталкиваясь ногами от земли) и т.д.

Функционируя согласно законам языковой системы, потенциальные слова отражают тенденции развития языка и наряду с узуальными производными и сложными словами верифицируют богатый лингвокреативный потенциал английских художественных онимов.

\section{Взаимодействие языковых и когнитивных механизмов при порождении этноконнотации художественными онимами}

При рассмотрении с позиций когнитивной лингвистики словообразовательная деривация художественных онимов служит репрезентацией концептуальной деривации, осуществляемой посредством двухуровневого процесса концептуальной интеграции. Определение особенностей взаимодействия семантики производящей основы и словообразовательного форманта или двух производящих основ позволяет выявить стоящие за ними концептуальные структуры, а также когнитивные механизмы метафоризации и метонимизации, предопределяющие формирование данных структур.

Аффиксация на когнитивном уровне предполагает метафоризацию концептуальной структуры, вербализованной производящей основой, англоязычным художественным онимом, и последующую интеграцию с ментальным пространством, вербализованным словообразовательным формантом. Например, производное прилагательное Strangelovian означает призывающий к ядерной войне и крупномасштабным разрушениям [24, p. 250] (здесь и далее перевод автора статьи. - О. С.) и содержит художественный оним Strangelove, имя эксцентричного ученого в фильме С. Кубрика “Dr. Strangelove or: How I Learned to Stop Worrying and Love the Bomb”. На первом этапе происходит фокусировка признака «сторонник ядерной войны» и в результате процесса 
концептуальной метафоризации формируется структура, которая объективируется этноконнотированным онимом Dr. Strangelove, означающим сумасшедший ученый, призывающий к ядерной войне. На втором этапе новая концептуальная структура интегрируется с концептуальной структурой, репрезентированной суффиксом -еsque, содержащей категориальный признак «сходство».

Усложнение когнитивной структуры характерно и для конверсии. Как отмечают Е. С. Кубрякова и В. А. Гуреев, данный способ словообразовательной деривации является результатом действия механизма метонимизации и «образования нового концептуального объединения гетерогенных концептов» [10, с. 37]. Так, конверсив to bunbury означает сочинять невероятные оправдания, чтобы избежать выполнения обязательств [16]. В первичной номинации художественный оним Bunbury - имя персонажа пьесы О. Уайльда “Тhe Importance of Being Earnest”. В результате процесса метафоризации при перспективизации признака «уклоняющийся от какоголибо дела» формируется новая структура, репрезентированная этноконнотированным онимом Bunbury человек, избегающий неприятных дел. На втором этапе данная структура претерпевает трансформацию под действием механизма когнитивной метонимии.

При словосложении и телескопии (слиянии усеченных основ или слов) сначала происходит интеграция концептуальных структур, стоящих за компонентами сложного слова или телескопизма (одним из которых является художественный оним английского языка), а затем метафоризация полученного бленда [12, с. 123]. Например, телескопизм Batmobile означает футуристический автомобиль [23, p. 37-38] и состоит из усеченных основ художественного онима Batman (имя супергероя в серии американских комиксов) и слова automobile.

\section{Продуктивность словообразовательных моделей и способов словообразовательной деривации вторичных художественных онимов}

Исследование когнитивных основ формирования производного значения художественных онимов при реализации их коннотативного потенциала предполагает выявление основных способов словообразовательной деривации изучаемых единиц.

Для наглядного представления полученные результаты обобщены в Таблице 1.

Таблица 1. Степень продуктивности способов словообразовательной деривации этноконнотированных художественных онимов

\begin{tabular}{|c|c|c|}
\hline \multicolumn{2}{|c|}{ Способ словообразования } & Колич. хар-ка (\%) \\
\hline \multirow[t]{2}{*}{ 1. Аффиксация } & 1.1. Межчастеречная & 45 \\
\hline & 1.2. Внутричастеречная & 21 \\
\hline \multicolumn{2}{|c|}{ 2. Словосложение } & 26 \\
\hline \multicolumn{2}{|l|}{ 3. Телескопия } & 4,5 \\
\hline \multicolumn{2}{|l|}{ 4. Конверсия } & 3,5 \\
\hline
\end{tabular}

Как показал проведенный нами анализ, аффиксация является наиболее продуктивным способом и составляет 66\% от общего количества исследованных примеров. Межчастеречная суффиксальная деривация осуществляется англоязычными художественными онимами по следующим словообразовательным моделям: $\mathrm{N}+$-ian $\rightarrow$ Adj (22,3\%), N + -ish (-aish) $\rightarrow$ Adj (10,3\%), N + -esque $\rightarrow$ Adj (5,2\%), N + -y $\rightarrow$ Adj (1,8\%), N + -ous $\rightarrow$ Adj $(1,8 \%), \operatorname{Adj}+$-ness $\rightarrow$ N (1,8\%) и Adj + -ism $\rightarrow$ N (1,8\%). Проиллюстрируем функционирование наиболее продуктивных словообразовательных формантов следующими примерами производных прилагательных: falstaffian - жизнерадостный, безнравственный [16] (производящая основа - художественный оним Falstaff, имя героя произведений У. Шекспира “Henry IV”, “The Merry Wives of Windsor”); milquetoasty - робкий, застенчивый [20] (Caspar Milquetoast - имя главного героя газетных комиксов “The Timid Soul”); pollyannaish чрезмерно оптимистичный (https://www.collinsdictionary.com/dictionary/english/pollyanna) (Pollyanna - героиня одноименного романа Э. Х. Портер, жизнерадостная 11-летняя девочка): I find it almost impossible to come to an optimistic conclusion in any argument; optimists always strike me as blindly Pollyannaish [22]. / Я нахожу практически невозможным приходить к оптимистичному выводу в любом споре; оптимисты всегда кажутся мне слепыми и слишком наивными.

Внутричастеречная суффиксальная деривация англоязычных художественных онимов, согласно результатам исследования, строится по следующим словообразовательным моделям: N1 + -ism $\rightarrow \mathrm{N} 2$ (9,8\%), N1 + -ry $\rightarrow$ $\mathrm{N} 2(4,2 \%), \mathrm{N} 1+$-ist $\rightarrow \mathrm{N} 2$ (3,4\%), N1 + -ite $\rightarrow \mathrm{N} 2$ (1,8\%), N1 + -dom $\rightarrow$ N2 (1,8\%). Так, дериват таlapropism означает ошибочное, неправильное употребление слов [16]. Производящее существительное - художественный оним Mrs Malaprop, имя персонажа пьесы Р. Шеридана 'The Rivals', речь которой изобилует ошибками: With his love of wordplay, Dahl would scribble his words on yellow pages from the American legal pads he used to write in, swapping letters around and adopting spoonerisms and malapropisms [19]. / Будучи неравнодушным к игре слов, Даль (Роальд Даль) записывал свои слова на желтых страницах американских линованных блокнотов, которыми он зачастую пользовался, меняя местами буквы и применяя намеренную перестановку звуков или ошибочные формы слов.

Словосложение представляет собой не менее продуктивный способ словообразования и составляет $26 \%$ от общего количества исследованных примеров. Как показал проведенный анализ, композиты, содержащие художественные онимы, строятся по наиболее продуктивной словообразовательной модели в системе 
современного английского языка - N1 + N2 $\rightarrow$ N3. Так, сложное слово Robin Hood tax означает налог на финансовые операции, взимаемый с состоятельных граждан и используемый для помощи нуждающимся [18]. В первичной номинации Robin Hood - герой средневековых английских легенд. В сознании коммуникантов фокусируются признаки «отбирающий деньги у богатых», «помогающий бедным»: A Robin Hood tax could turn banks from villains to heroes [15]. / Налог Робин Гуда может превратить банки из злодеев в героев.

Формирование производных единиц, созданных посредством телескопии (слияния), происходит по двум словообразовательным моделям: усеченная основа + основа $(3,4 \%)$ и усеченная основа + усеченная основа $(1,1 \%)$. Полученные результаты позволяют судить о проявлении принципа экономичности английского языка, его стремлении к моносиллабизму. Например, Frankenfood означает генномодифицированные продукты питания, особенно фрукты или овощи [18]. Производное слово состоит из усеченной основы художественного онима Frankenstein (герой произведения М. Шелли “Frankenstein; or, the Modern Prometheus”) и основы food. В сознании носителей языка актуализируется признак «созданный искусственно»: Critics considered the new "Frankenfoods" an affront to nature and a hazard to the environment [14]. / Критики считали новые генномодифицированные продукты оскорблением природы и угрозой для окружающей среды.

При исследовании конверсии вторичных художественных онимов нами выявлены случаи транспозиции в класс глаголов $(\mathrm{N} \rightarrow \mathrm{V})$. Несмотря на то, что данный способ словообразовательной деривации показывает низкую продуктивность при рассмотрении узуальных дериватов (3,5\%), конверсия составляет более 50\% от общего количества изученных окказиональных единиц, что доказывает активность данного способа словообразования, который является характерной чертой развития современного английского языка.

\section{Заключение}

Проведенное исследование позволяет сделать следующие выводы.

При словообразовательной деривации англоязычных художественных онимов актуализируется коннотативный компонент в структуре значения, детерминированный национально-культурной спецификой восприятия мира народом, а также системой ценностных установок. Выявленные производные художественные онимы, композиты и телескопизмы показывают высокую продуктивность при вербализации новых структур сознания.

Когнитивным основанием словообразовательной деривации служит процесс концептуальной интеграции, осуществляемый в два этапа, при котором задействуются когнитивные механизмы метафоризации и метонимизации.

Анализ контекстов употребления показал, что этноконнотированные дериваты востребованы как у представителей британской, так и американской лингвокультур при выборе необходимых средств номинации окружающей действительности. Коннотативный репертуар художественных онимов обогащается за счет различных способов словопроизводства, наиболее продуктивными из которых являются аффиксация (66\%) и словосложение (26\%). Выявленные словообразовательные модели и способы словообразования соответствуют основным тенденциям развития современного английского языка. Большое количество окказионализмов (125 единиц) свидетельствует о креативном характере языковой деятельности и богатом коннотативном потенциале исследуемых имен собственных.

Перспективы дальнейшего исследования мы видим в изучении дискурсивных особенностей реализации коннотативного потенциала художественными онимами в процессах семантической и словообразовательной деривации; в изучении специфики перевода этноконнотированных единиц и их дериватов.

\section{Список источников}

1. Бабина Л. В. Когнитивный подход к исследованию мотивированности производного слова // Когнитивные исследования языка. 2012. Вып. 12. С. 65-73.

2. Бабина Л. В., Паршина Е. О. Когнитивные основания апеллятивов, образованных от имен собственных // Вопросы когнитивной лингвистики. 2012. Вып. 3. С. 23-31.

3. Беляевская Е. Г. Понятие коннотации с когнитивной точки зрения // Концептуальное пространство языка: сборник научных трудов. Тамбов: ТГУ, 2005. С. 53-66.

4. Болдырев Н. Н. Концептуальная деривация как основа вторичной языковой интерпретации // Когнитивные исследования языка. 2018. № 33. С. 37-42.

5. Быкова О. И. Этноконнотация как вид культурной коннотации: на материале номинативных единиц немецкого языка. Воронеж: Воронежский государственный университет, 2005. 277 с.

6. Говердовский В. И. Коннотемная структура слова. Х.: Выща школа; Издательство при Харьковском государственном университете, 1989. 92 с.

7. Ирисханова О. К. О теории концептуальной интеграции // Известия Академии наук. Серия литературы и языка. 2001. Т. 60. № 3. С. 44-49.

8. Калинкин В. М. Поэтика онима. Донецк: Юго-Восток, 1999. 408 с.

9. Кубрякова Е. С. Язык и знание: на пути получения знаний о языке: части речи с когнитивной точки зрения: роль языка в познании мира. М.: Языки славянской культуры, 2004. 555 с. 
10. Кубрякова Е. С., Гуреев В. А. Конверсия в современном английском языке // Вестник Воронежского государственного университета. Серия «Лингвистика и межкультурная коммуникация». 2002. № 2. С. 33-38.

11. Кустова Г. И. Типы производных значений и механизмы языкового расширения. М.: Языки славянской культуры, 2004. 472 с.

12. Сухарева О. В. Коннотативность художественных онимов английского языка: дисс. ... к. филол. н. Воронеж, 2014. 273 с.

13. Телия В. Н. Коннотативный аспект семантики номинативных единиц. М.: Наука, 1986. 141 с.

14. A plant of last resort [Электронный ресурc]. URL: https://www.chicagotribune.com/opinion/ct-xpm-2011-10-01ct-oped-1002-cassava-20110930-story.html (дата обращения: 18.11.2020).

15. A Robin Hood tax could return the banks from villains to heroes [Электронный ресурс]. URL: https://www.theguardian. com/commentisfree/2011/sep/28/robin-hood-tax-bankers-villains-heroes (дата обращения: 25.10.2020).

16. Collins English Dictionary [Электронный ресурc]. URL: http://www.collinsdictionary.com (дата обращения: 25.11.2020).

17. Keep the kids busy with Answer Angel's help [Электронный ресурс]. URL: https://www.chicagotribune.com/ news/ct-xpm-2008-12-25-0812220208-story.html (дата обращения: 18.11.2020).

18. Longman Dictionary of Contemporary English [Электронный ресурс]. URL: https://www.ldoceonline.com (дата обращения: 11.12.2020).

19. Roald Dahl's swashboggling words get their own dictionary? [Электронный ресурc]. URL: https://www.bbc.com/ news/entertainment-arts-36397983 (дата обращения: 20.11.2020).

20. The American Heritage Dictionary of the English Language [Электронный ресурc]. URL: https://www.ahdictionary. com/ (дата обращения: 19.11.2020).

21. The Dictionary of English Slang [Электронный ресурс]. URL: https://slangdefine.org (дата обращения: 18.11.2020).

22. The end is nigh [Электронный ресурc]. URL: https://www.theguardian.com/Columnists/Column/ 0,5673,543043,00.html (дата обращения: 30.10.2020).

23. The Oxford Dictionary of Reference and Allusion / ed. by A. Delahunty et al. N. Y.: Oxford University Press, 2010.406 p.

24. Webber E. Merriam-Webster's Dictionary of Allusions. Springfield, Mass.: Merriam-Webster, 1999. 592 p.

\section{Информация об авторах | Author information}

RU Сухарева Ольга Вадимовна ${ }^{1}$, к. филол. н.

${ }^{1}$ Воронежский государственный университет

EN Sukhareva Olga Vadimovna ${ }^{1}, \mathrm{PhD}$

${ }^{1}$ Voronezh State University

${ }^{1}$ sukhareva-ov@yandex.ru

\section{Информация о статье | About this article}

Дата поступления рукописи (received): 13.12.2020; опубликовано (published): 09.04.2021.

Ключевые слова (keywords): этноконнотация; художественный оним; словообразовательная деривация; концептуальная деривация; ethnic connotation; literary onym; word-formative derivation; conceptual derivation. 